\section{Política e intermedicalidade no Alto Xingu: do modelo à prática de atenção à saúde indígena}

\author{
Politics and inter-medicality in the Upper Xingu: \\ from model to practice in indigenous health care
}

Marina Pereira Novo ${ }^{1}$

\title{
Introdução
}

1 Ministério do

Desenvolvimento Social e Combate à Fome, Brasília, Brasil.

Correspondência M. P. Novo

Ministério do Desenvolvimento Social e Combate à Fome. Esplanada dos Ministérios, Bloco A, sala 323, Brasília, DF 70054-906, Brasil. mapnovo@gmail.com

\begin{abstract}
The indigenous healthcare model in Brazil is premised on comprehensive care combined with the notion of differentiated care and provides for respect for cultural diversity, seeking to incorporate traditional therapeutic practices into the health services that serve indigenous peoples. This study aimed to determine how to reconcile universal access to health goods and services with a model of care that guarantees differentiation, without interfering in the quality of services. It is also necessary to define which parameters should be used for evaluating the quality and efficacy of such services in an intercultural context. Based on a case study - the implementation of health services in the Upper Xingu - the author addresses some issues related to the political uses and "dangers" associated with "health spaces" and the distinct concepts (indigenous and non-indigenous) of what constitutes health and quality of health services. These issues affect not only health services but also the local political situation.
\end{abstract}

Indigenous Health; Health Care (Public Health); Health Care Quality, Access, and Evaluation
A temática da saúde indígena no Brasil ganhou força no debate político nacional em meados da década de 1980, durante o processo de redemocratização. Nesse mesmo período, também ganhava espaço nas discussões políticas o movimento de reforma sanitária que tinha por fundamentos os princípios do modelo internacional da política de cuidados primários de saúde, proposta pela Organização Mundial da Saúde (OMS) por meio da Declaração de Alma-Ata. Os princípios e diretrizes expostos nesse texto previam: o acesso integral e igualitário às ações e serviços de saúde; a criação de redes regionalizadas e hierarquizadas de atendimento; a descentralização; a participação comunitária por intermédio do chamado "controle social"; e, por fim, a atenção integral à saúde 1 .

Durante esse período, o surgimento e o desenvolvimento das organizações indígenas impulsionaram ainda mais os debates e, em função disto, foi possível um avanço nas discussões em relação à atenção à saúde indígena, culminando na realização da I Conferência Nacional de Proteção à Saúde do Índio, em novembro de 1986. Essa conferência estabeleceu as bases para a criação de um subsistema específico para a atenção à saúde do índio dentro do sistema nacional de saúde, propondo a "estruturação de um modelo de atenção diferenciada, baseado na estratégia de Distritos Sanitários Especiais Indígenas, como 
forma de garantir aos povos indígenas o direito ao acesso universal e integral à saúde, atendendo às necessidades percebidas pelas comunidades e envolvendo a população indígena em todas as etapas do processo de planejamento, execução $e$ avaliação das ações" 2 (p. 8).

Nesse contexto político, cresce, portanto, a importância dos movimentos indigenistas que deixam de tomar as questões de saúde indígena somente como "uma questão de saúde" - no sentido de lhes proporcionar apenas melhores condições sanitárias e epidemiológicas -, passando a perceber e utilizar este espaço como um dos principais instrumentos de inserção no contexto político nacional, enfatizando suas reivindicações por autonomia e pela autogestão das atividades e recursos. Essas discussões culminaram nas proposições estabelecidas na Constituição Federal de 1988 e nas regulamentações posteriores, que previam uma nova forma de agenciamento da saúde nacional e consequentemente da saúde indígena, baseada nos pressupostos de “acesso universal e integral à saúde". A partir de 1990, finalmente, com a Lei $n^{\circ} .8080^{3}$, uma nova forma de política pública de saúde passou a ser posta em vigor por meio da criação do Sistema Único de Saúde (SUS), do qual a saúde indígena passou a fazer parte.

A partir desse momento, ao mesmo tempo em que o atendimento à saúde do índio passou a fazer parte do SUS - que visa a um acesso igualitário aos serviços de saúde -, as populações indígenas também tiveram garantidos na Constituição Federal não só o direito ao acesso diferenciado a estes serviços como forma de reconhecer e garantir "sua organização social, costumes, línguas, crenças e tradições”, como também à ampliação (ao menos em teoria) de sua participação na proposição e deliberação a respeito das políticas de saúde, por meio da criação dos Conselhos responsáveis pelo controle social.

Apesar de todos esses avanços, somente em 1999 é que se concretiza efetivamente a instauração de um Subsistema de Atenção à Saúde Indígena, por meio da criação de 34 Distritos Sanitários Especiais Indígenas (DSEI) que deveriam funcionar como interlocutores diretos das comunidades indígenas com as diversas instâncias governamentais 4,5,6. De acordo com sua concepção, esses Distritos são "um modelo de organização de serviços - orientado para um espaço etnocultural dinâmico, geográfico, populacional e administrativo bem delimitado -, que contempla um conjunto de atividades técnicas, visando medidas racionalizadas e qualificadas de atenção à saúde, promovendo a reordenação da rede de saúde e das práticas sanitárias e desenvolvendo atividades administrativo-gerenciais necessárias à prestação da assistência, com controle social" 7 (p. 13).

Considerando-se essas proposições, a grande questão que se coloca relativa à criação desse subsistema de atenção à saúde é entender de que forma é possível conciliar o acesso universal aos bens e serviços de saúde a uma atenção que garanta a diferenciação, sem interferir, no entanto, na qualidade dos serviços ofertados. Mais do que isso, que parâmetros utilizar para avaliar a qualidade e a eficácia desses serviços ofertados em um contexto intercultural?

Diversas questões merecem destaque nesse processo que, como qualquer processo que envolva o contato intercultural, apresenta conflitos e ambiguidades que são gerenciados de maneiras distintas pelos diferentes atores envolvidos. Na região do Alto Xingu essa relação entre diversidade e universalidade não se dá de forma menos complexa, explicitando alguns conflitos e paradoxos inerentes ao modelo proposto pelos órgãos gestores da política de saúde no Brasil, como pretendo mostrar a seguir.

\section{O Alto Xingu}

O Parque Indígena do Xingu é uma reserva federal criada em 1961, situada ao norte do Estado do Mato Grosso, Região Centro-oeste do Brasil. Em seus aspectos sociopolíticos, o Parque pode ser dividido em três partes, tendo em vista os povos que lá habitam: uma ao norte, conhecida como Baixo Xingu; uma na região central, o chamado Médio Xingu; e outra ao sul, o Alto Xingu, região que, apesar das diferenças linguísticas, apresenta certa homogeneidade no que diz respeito à sua forma de organização sociopolítica. Compõem essa região do Alto Xingu nove povos distintos que podem ser divididos em quatro grupos de acordo com sua variação linguística: línguas da família Aruak - Yawalapiti, Mehinako, Waurá; línguas do tronco Tupi - Kamayurá e Aweti; e línguas da família Karib - Kalapalo, Kuikuro, Nahukuá, Matipu. De acordo com informações obtidas junto ao órgão responsável pela oferta de serviços de saúde na região, a população altoxinguana era, em 2007, de cerca de 2.720 pessoas, distribuídas em 27 aldeias.

Os serviços de saúde na região do Alto Xingu são coordenados pelo DSEI Xingu, mas são executados localmente por uma organização não-governamental (ONG) coordenada e gerida pelos próprios alto-xinguanos. É essa ONG que responde pela contratação dos profissionais que compõem a Equipe Multidisciplinar de Saúde Indígena (EMSI) - médico, enfermeiros, técnicos e auxiliares de enfermagem, além dos agentes in- 
dígenas de saúde (AIS) -, responsável pela oferta dos serviços na região.

\section{Metodologia e referencial teórico}

Esta pesquisa foi realizada entre os anos de 2006 e 2008, ao longo do desenvolvimento de meu trabalho de mestrado. Com a finalidade de realizar a pesquisa, utilizei diversas técnicas, que vão desde a observação direta dos trabalhos da equipe de profissionais que atua na região, passando por entrevistas informais ou formais com estes atores, com representantes de diversas etnias e com lideranças/caciques, autoridades e representantes dos órgãos gestores da saúde, além da análise de documentos produzidos por estes órgãos e pelos próprios indígenas.

Meu principal espaço para observação da relação intercultural que se estabelece nesse contexto de atenção à saúde no Alto Xingu foi o Posto Indígena Leonardo. Esse Posto foi criado no ano de 1946, com a intenção de funcionar como um polo de agregação das aldeias alto-xinguanas, e acabou por se tornar o centro da distribuição de benefícios provenientes do "mundo ocidental" - especialmente medicamentos e instrumentos de trabalho industrializados. Esse é um lugar privilegiado de contato entre os conhecimentos e práticas tradicionais e os conhecimentos e práticas ocidentais dentro do território indígena, uma vez que lá se concentram as "informações trazidas das cidades" por meio da grande circulação de pessoas (e consequentemente de notícias e fofocas), da realização de cursos de formação de AIS e professores, além de ser o lugar onde se realizam as reuniões dos conselhos, ou mesmo onde permanece a equipe de saúde multidisciplinar para realizar os atendimentos. Por essas características, para melhor definir esse local utilizo a noção de fronteira, ou seja, "um espaço de encontro entre dois mundos, duas formas de saber, ou ainda, múltiplas formas de conhecer e pensar o mundo: as tradições de pensamento ocidentais (...) e as tradições indígenas" 8 (p. 47).

O Posto é, por excelência, um espaço de fluidez e trocas entre diferentes grupos culturais na medida em que foi criado no contexto do contato e tornou-se elemento de fundamental valor para os grupos alto-xinguanos, tanto no que diz respeito às relações internas a esse sistema interétnico quanto no que diz respeito aos espaços de negociação com organismos governamentais e não-governamentais dentro de um contexto político mais amplo. A questão da interculturalidade, ou da intermedicalidade (conforme definido por Follér 9), está posta na medida em que estamos tratando de um espaço onde convivem e se impõem dois modelos distintos de se pensar a "saúde": de um lado, aparecem os conceitos próprios do modelo sanitarista nacional - conceitos estes que se apresentam localmente por meio dos cursos de formação de AIS, bem como por intermédio da atuação de profissionais não indígenas em território indígena; do outro lado, esta discussão remete às concepções internas às sociedades indígenas com suas terapêuticas tradicionais vinculadas à cosmologia, à organização sociopolítica e ao ethos local, além das diversas incorporações e ressignificações que são feitas dos elementos provenientes da medicina ocidental - entendida aqui como sinônimo de biomedicina, em contraposição às chamadas "terapêuticas tradicionais".

O referencial teórico desta pesquisa está ancorado nos conceitos da Antropologia da Saúde, compreendendo a noção de cultura enquanto um sistema de símbolos que fornece um modelo "de" e um modelo "para" a realidade. Nesse sentido, considero que os significados dos eventos culturais, incluindo os processos de saúde/ doença, emergem da relação que se estabelece entre os indivíduos em um processo de significação e ressignificação contínuo que ocorre dentro das possibilidades lógicas internas aos grupos sociais. Desse modo, em momentos e espaços onde se efetivam as relações entre diferentes sistemas terapêuticos, há uma participação ativa de ambas as partes, que atribuem significados às experiências vividas e possibilitam, assim, a criação de sistemas híbridos de tratamento 8 . Essa hibridização tem ocorrido com frequência nos mais diversos agrupamentos indígenas, mas gera conflitos no que diz respeito às diferentes expectativas que se criam a respeito das políticas públicas de saúde, especialmente pelo fato de tais políticas serem em sua maioria orientadas por princípios tecnicistas fundamentados nos termos da biomedicina. Nesse sentido, cabe inclusive o questionamento a respeito da forma como os serviços são normalmente avaliados, propondo-se a incorporação do ponto de vista das populações atendidas, a fim de que se possa, cada vez mais, aprimorar os serviços de saúde 10 .

Também nesse sentido é importante recuperar os discursos "nativos" como uma forma de respeitar seus pontos de vista, "não como estratégia de dominação, mas para modificar os pontos de estrangulamento dos serviços a que ela tem direito e que deve reivindicar" 11 (p. 236). Isso faz com que a política de saúde não seja entendida "apenas como uma ação de estado em direção à população, mas como um direito para o qual ela deve opinar em termos de efetividade e qualidade" 11 (p. 236), colaborando para a implementação de uma efetiva atenção diferenciada em saúde. 
Autores como Augé 12, Buchillet 13, Garnelo 14, Langdon 15, Langdon \& Garnelo 16 e Santos \& Coimbra Jr. 17, dentre outros, contribuem e reforçam esse tipo de interpretação.

\section{Os espaços da saúde e seus "perigos": estrutura física e relações políticas}

O Posto Indígena Leonardo contava à época da realização desta pesquisa com cerca de vinte diferentes construções que serviam como moradia, escola, casa do rádio, alojamento, refeitório/cozinha, além do posto de saúde (ou unidade básica de saúde - UBS) e a Casa de Saúde Indígena (Casai), utilizada como alojamento para os pacientes internados (em tratamento) no Posto.

Um olhar mais atento a essa estrutura física já permite perceber algumas incongruências relacionadas ao discurso oficial que faz referência à atenção diferenciada, sendo marcado, no entanto, pela questão "cultural” e da "manutenção de tradições", sem deixar claro o que isto implica na prática ${ }^{18}$. Essas indefinições acabam gerando conflitos de interesses com as populações indígenas que reivindicam o acesso a serviços de saúde com qualidade e, ao mesmo tempo, que garantam suas especificidades. Um dos claros exemplos desse "descompasso" de expectativas está na antiga Casai do Posto Leonardo, construída dentro dos moldes "tradicionais" de casas, com uma estrutura em madeira e a cobertura feita em sapé. Quando os órgãos responsáveis pelos atendimentos propõem e constroem uma casa que deve abrigar os pacientes que estão em tratamento no Posto Leonardo nesses moldes, há uma clara pretensão de "reforçar as tradições", deixando de lado, entretanto, uma série de fatores considerados de extrema importância pelos alto-xinguanos, sendo este local considerado por eles como inapropriado por diversas razões. Uma das questões vistas como um problema pelos pacientes são as noites frias, especialmente durante os meses de maio a setembro, não havendo uma estrutura apropriada (como há nas casas "tradicionais" das aldeias) para fazer fogueiras em função da quantidade de pessoas ali hospedadas e do fato de abrigar muitos pacientes com problemas nas vias respiratórias, sendo impedidos pelos profissionais de saúde de fazerem tais fogueiras para "não piorar a situação de saúde". Uma das soluções encontradas pelos pacientes foi, contrariando as indicações dos enfermeiros, arrancar as madeiras que serviam de paredes da Casai para fazer fogueiras, tendo sido esta atitude interpretada pelos profissionais da EMSI como "vandalismo" ou "depredação" - como se simplesmente os indígenas não valorizassem o "patrimônio que possuem".

Outra dificuldade vivenciada pelos alto-xinguanos em relação a esse espaço diz respeito à forma como se realiza a internação de pessoas - preocupação extensível ao Posto Leonardo como um todo -, na medida em que implica a convivência forçada entre índios de diferentes etnias que se encontram em uma situação liminar de doença. Essa preocupação pode ser compreendida porque, no contexto sociocosmológico alto-xinguano, a doença é entendida "como uma agressão externa à pessoa, materializada na forma de objetos ou substâncias introduzidas no corpo do doente" 19 (p. 65). Essa agressão originase ou pela ação de espíritos devido à quebra de regras restritivas, ou pela feitiçaria, creditada à prática malévola de outros índios "invejosos". Os momentos liminares da vida de uma pessoa (sejam eles a reclusão pubertária, a menstruação feminina e o pós-parto, além das ocasiões de adoecimento) são considerados extremamente delicados, pois favorecem a atuação desses espíritos que causam doenças e podem "roubar $a$ alma das pessoas" 20,21. Esses espíritos agem sozinhos ou em conjunto com feiticeiros, exigindo o cumprimento de um número considerável de restrições alimentares e sexuais por parte do doente e de seu grupo de substância, ou seja, todos aqueles que compartilham substâncias corporais (sangue, sêmen, leite e outros alimentos) entre si. Esse compartilhamento de substâncias, por sua vez, faz com que as ações de cada um interfiram diretamente tanto no processo de adoecimento quanto no tratamento e na cura do doente 22 .

De acordo com essa concepção de doença, a permanência no Posto Leonardo, acompanhada do contato direto com índios de outras etnias e aldeias durante um processo de adoecimento pode se tornar potencialmente perigosa porque não somente impede o cumprimento das restrições impostas (já que torna-se praticamente impossível a ingestão somente de alimentos "permitidos", tanto pelo paciente quanto por todo o seu grupo de substância) como também força uma aproximação com fontes potenciais de adoecimento e feitiçaria - os índios provenientes de outras aldeias e etnias.

Em diversos momentos essa noção de perigo relacionada ao espaço do Posto é colocada em evidência, marcando a forma como as pessoas interagem com este espaço e com as pessoas que lá habitam e circulam. Considero que essa noção de perigo remete a uma discussão mais ampla a respeito da demarcação de fronteiras identitárias (internas e externas ao sistema xinguano), demarcações estas que subjazem a grande parte das acusações de feitiçaria, sendo possível se ob- 
servar a presença marcante de um denominador hierárquico étnico.

O contato (e as disputas) interétnicos entre os alto-xinguanos parecem estar associados à noção de "perigo" - e às consequentes acusações mútuas de feitiçaria - desde o período de aproximação destes povos e de formação de uma "comunidade moral" na região que remetem a finais do século XIX. Esse processo de "pacificação" ou de "xinguanização" dos povos que ali se aproximavam diz respeito, por sua vez, à ideia de "virar gente", deixar de ser "índio bravo" e, portanto, se adaptar a um ethos pretensamente pacífico que é marca da "identidade xinguana" atual 23.

As acusações interaldeias que marcam as alteridades internamente ao sistema alto-xinguano são salientadas em espaços considerados neutros, ou seja, aqueles que a princípio não pertencem a nenhuma etnia específica, como é o caso do Posto Leonardo. Esses locais "neutros" - aqui classificados como espaços de fronteira na medida em que permitem o "fluxo de pessoal e conhecimento e onde as diferenças sociais são construídas" 9 (p. 65) - impedem a efetivação do processo de segmentação hierárquica interaldeias, no momento em que impossibilitam delimitações territoriais e espaciais (entendido aqui em um sentido mais amplo, compreendendo também o espaço sociocosmológico), fornecendo em um momento posterior as condições para a exacerbação de tais diferenciações que se materializam nas acusações mútuas de feitiçaria. Tais diferenciações, que são feitas mais facilmente nos espaços das aldeias, geram uma relação complexa neste contexto (espacialmente definido) interétnico, que é ao mesmo tempo fonte de bens e serviços, mas também perigoso e passível de causar ou potencializar processos de adoecimento e de morte.

Como se percebe até este ponto, tratar da questão da saúde implica tratar não apenas dos atendimentos realizados e dos serviços ofertados, mas fundamentalmente de tentar compreender como se relacionam as distintas formas de se pensar a saúde e de se "fazer" a saúde nesse contexto específico. Nesse sentido, cabe também uma discussão a respeito da forma como cada um dos atores avalia os serviços prestados, explicitando ainda mais essas diferenças.

\section{Sobre as diferentes avaliações dos serviços de saúde}

Não pretendo neste espaço avaliar propriamente os serviços de saúde oferecidos à população alto-xinguana, mas pretendo, partindo desses elementos mostrados até agora e com base nos referenciais teóricos apresentados, levantar questionamentos a respeito dos critérios utilizados pelos profissionais e usuários do sistema de saúde para avaliar estes serviços, apreendidos por meio de seus discursos e ações, e que possibilitam também a observação das diferentes lógicas que estão em jogo quando se discute saúde indígena.

As avaliações "oficiais" dos serviços e da situação de saúde do Alto Xingu são feitas pelos gestores do DSEI, com base nas informações estatísticas coletadas pelos próprios profissionais e agentes de saúde por meio de seu trabalho cotidiano. Os AIS preenchem relatórios mensais com informações sobre os atendimentos realizados, que são transformados posteriormente em dados estatísticos para justificar as prestações de contas e mesmo as previsões de gastos para os próximos períodos de convênio da ONG responsável pela prestação de serviços de saúde. Com relação a isso, os profissionais e gestores afirmam que "sem dados não vem dinheiro do governo", ou seja, sem as informações estatísticas que "comprovem" a qualidade dos serviços prestados, não são feitos novos investimentos por parte do Governo Federal.

Quando questionados a respeito da "situação de saúde geral” no Alto Xingu, os profissionais muitas vezes, apesar de criticarem a infraestrutura considerada precária, ressaltam que estão cada vez mais "conseguindo realizar o trabalho" e que por isto "a saúde está melhorando", dando como exemplo as campanhas de coleta de exames preventivos de câncer de colo de útero e principalmente as campanhas de imunização - de acordo com dados oficiais, as últimas campanhas de imunização atingiram uma cobertura vacinal de praticamente $90 \%$ da população alto-xinguana, proporção superior às atingidas nas realizadas junto à população nacional. Essas campanhas de vacinação organizadas pelo DSEI são vistas com bons olhos também pelas lideranças indígenas que, junto com os AIS, "ajudam a convencer as pessoas de suas aldeias que não querem participar".

Os discursos das lideranças e da população em geral em relação à avaliação dos serviços também são sempre no sentido de se reforçar a melhora no estado geral da saúde no Alto Xingu nos últimos anos, mas baseando-se em outros critérios. Os alto-xinguanos valorizam nesses discursos o processo crescente de medicalização - muito criticado pelos profissionais -, conforme ressalta um dos Agentes de Saúde: “Antes não tinha remédio. Essa farmácia estava sem medicação, sem nada. Agora melhorou bastante. Tem muita medicação aí que a gente precisa", além de destacarem a importância da mudança de com- 
portamento percebida em relação à equipe de saúde que "agora visita as aldeias" - e que, portanto, está “mais próxima do índio”.

Essa mudança de atitude dos profissionais é vista de forma positiva pela população local, que percebe neste processo não apenas um ganho qualitativo "na saúde", mas também em relação à sua situação política dentro do contexto nacional de garantia de direitos diferenciados e que possam, em alguma medida, ser controlados pelas próprias populações e lideranças indígenas.

Todavia, apesar dessa valorização, a atuação dos profissionais de saúde e sua relação com a população local estão marcadas por diversas controvérsias e desentendimentos. Não obstante a permanência prolongada dos profissionais em campo, não é raro ouvir reclamações por parte dos índios, afirmando que os profissionais permanecem apenas no Posto Leonardo e não acessam as aldeias com frequência.

Nesse sentido, para as lideranças a situação considerada ideal é a permanência contínua destes profissionais nas aldeias, demanda que pode ser constantemente ouvida. Essa demanda está diretamente relacionada ao papel político desempenhado pelas lideranças dentro do sistema alto-xinguano, reforçando o princípio difundido entre eles de que o controle e a posse de bens auxiliam na garantia de legitimidade e poder - não só dentro das aldeias, mas também na relação com os não índios. "Possuir" um profissional na aldeia é uma das maneiras das lideranças exercerem não só o seu papel de "provedores" - já que predomina entre os alto-xinguanos o discurso de que são eles que "conseguem" os profissionais por meio de suas relações pessoais - como também possibilita uma maior autonomia com relação ao Posto e ao DSEI, cumprindo funções políticas na medida em que reforçam também suas requisições por atendimentos e serviços de melhor qualidade. $\mathrm{O}$ acesso a esses profissionais e serviços, por sua vez, geralmente se vê garantido porque remete a relações de parentesco e aliança com outras lideranças ou mesmo com representantes dos responsáveis pela execução da política de saúde, com quem mantêm relações de reciprocidade e "endividamento". Essas relações entre "parentes" (especialmente afins reais ou classificatórios), assim como as relações de "amizade", são marcadas por ciclos necessários de prestações e contraprestações por meio de "presentes" ou "favores" que devem, portanto, ser retribuídos, criando essa relação de "endividamento" a que me referi. Nesse sentido, todos os profissionais presentes nas aldeias (para além inclusive dos profissionais de saúde), são vistos como recursos muito importantes e estão, portanto, em processo contínuo de negociação.
Os profissionais, por sua vez, não se reconhecendo como recursos, compreendem e explicam a importância de sua permanência nas aldeias sob a ótica de garantia das necessidades estratégicas de atendimento (ou seja, para "garantir a cobertura dos atendimentos"), estando, ao mesmo tempo, condicionada a uma noção vaga de "boas condições de trabalho". Essa noção é entendida por eles como a existência de um local específico para sua moradia nas aldeias - espaço este que deve ser fisicamente separado da área dos atendimentos -, mas também envolve a manutenção de "boas relações" com as chefias das aldeias, para que seja possível realizar o trabalho.

De acordo com os profissionais, as frequentes brigas entre eles e as lideranças indígenas parecem ser um dos principais entraves à sua permanência nas aldeias. Os desentendimentos ocorrem em grande parte por um motivo principal: os arranjos políticos locais que envolvem a reivindicação por uma maneira específica de atuação desses profissionais brancos junto à população atendida. As questões mais valorizadas pelos alto-xinguanos com relação ao trabalho da EMSI são a distribuição de medicamentos - vista pelos profissionais como muito negativa, como já ressaltei em outro momento - e o acesso que esses profissionais possibilitam aos serviços de saúde nas cidades próximas. Seu trabalho é apropriado muito mais como elemento político de acesso a bens e serviços e de legitimação das posições de liderança, contrastando com uma visão que privilegia mais a questão técnica dos atendimentos e da rede hierarquizada de serviços.

Esse tipo de expectativa (que muitas vezes se traduz em exigência) por parte das lideranças e das comunidades cria desentendimentos com os profissionais que, com uma racionalidade técnico-burocrática característica do modelo ocidental de prestação de serviços de saúde, não se submetem às imposições feitas, gerando uma incompatibilidade de demandas (e, consequentemente de avaliações) com relação ao trabalho de saúde.

Paralelamente, os depoimentos dos profissionais mostram a expectativa de uma urgente transformação dos hábitos a fim de se adequarem aos preceitos (biomédicos) de higiene, ressaltando a importância da participação dos AIS neste processo. "Acho necessário que eles [os índios] mudem de hábitos. (...) O AIS é índio e não vai deixar de ser índio. Mas ele tem que aprender um pouco..." (Médico).

O fato de os profissionais estabelecerem julgamentos morais a respeito do comportamento e de certos procedimentos terapêuticos, acaba interferindo nas relações que estabelecem com os índios e consequentemente nas escolhas feitas 
durante os processos de adoecimento. Além disso, ao dizer que "o AIS é índio e não vai deixar de ser índio”, percebe-se, além da expectativa sobre a mudança de hábitos, também a imposição de um modelo de concepção da identidade, característico da "civilização" ocidental, que enxerga os índios como "primitivos" que precisam, portanto, "ser civilizados" por meio da "aquisição" dos conhecimentos biomédicos ocidentais.

Os alto-xinguanos definem esse tipo de postura da equipe como descaso, e reforçam constantemente a diferença da situação do trabalho na aldeia em relação à cidade. E nesse sentido, os próprios alto-xinguanos também cobram uma mudança de atitudes por parte dos profissionais, que devem "aprender a trabalhar no Alto Xingu", o que significa conhecer a cultura e se adequar às demandas locais, como se oberva na fala de um auxiliar de enfermagem indígena.

"Primeiro ele [médico] era muito difícil. Ele não ia na casa dos pacientes que tem lá no Leonardo e não dava remédio à noite. (...) Ele diz que é médico. Ele atendia paciente do jeito que os médicos atendem na cidade, no hospital. Aí expliquei pra ele que não é assim, aqui é diferente, não é hospital, aquié o Xingu. Você tem que mudar seu trabalho (...). Ele mudou um pouquinho" (Auxiliar de Enfermagem Indígena; grifo meu).

Essa fala é extremamente significativa para se perceber a disputa que está em jogo entre diferentes concepções acerca de "saúde", da qualidade dos serviços e dos processos de adoecimento e cura. Ao dizer que o médico "diz que é médico", esse auxiliar de enfermagem indígena (teoricamente um representante da "medicina ocidental" em sua aldeia) reforça que "ser médico no Xingu é diferente”, ou seja, que a legitimação de seu trabalho mantém relações profundas com sua atuação nos termos dos próprios índios, devendo responder a demandas específicas que nem sempre condizem com as expectativas da medicina ocidental. Para ser considerado um médico, ele precisa "se fazer médico em sua atuação"; os profissionais precisam agir de uma forma distinta de quem trabalha na cidade para ter seu trabalho aceito e ter "o apoio necessário para trabalhar". Arrisco-me a dizer que esse discurso explicita a ideia de que "é preciso se tornar um pouco índio", e mais do que isto, tornar-se um alto-xinguano, para que o trabalho dos profissionais seja legitimado pelos índios. É quase como dizer que "o médico é branco e não vai deixar de ser branco, mas precisa aprender com o índio". Salta aos olhos a semelhança desse discurso com o que é proferido pelo médico quando diz que " $o$ Agente Indígena de Saúde é índio e não vai deixar de ser índio, mas precisa aprender um pouco". Trata-se de uma disputa entre diferentes esquemas lógico-simbólicos que operam, neste caso, arranjos semelhantes, com a inversão de símbolos.

Essas disputas estão diretamente relacionadas aos processos de saúde/doença, e são reconhecidas e administradas pelos alto-xinguanos em seu cotidiano, refletindo-se nas escolhas de itinerários terapêuticos ou nas disputas por profissionais, equipamentos e medicamentos. Os profissionais não indígenas, por sua vez, têm mais dificuldade em lidar com essa situação, o que se traduz na impossibilidade de criação de espaços para a construção de conhecimentos e de práticas conjuntas, como se propõe no modelo de atenção à saúde indígena em vigor.

Com base nessas observações, pode-se afirmar que o trabalho dos profissionais é apropriado pelos alto-xinguanos como elemento político de acesso a bens e serviços, de legitimação da posição dos líderes e de "alto-xinguanização" da alteridade, contrastando com uma visão que privilegia mais a questão técnica dos atendimentos e da rede hierarquizada de serviços. Os profissionais não indígenas, com uma racionalidade técnico-burocrática característica da medicina ocidental, não se submetem às imposições feitas, gerando uma incompatibilidade de expectativas (e, consequentemente de avaliações) com relação ao trabalho de saúde.

\section{Considerações finais}

Busquei aqui apresentar o modelo atual de atenção à saúde das populações indígenas no Brasil, e a situação específica da oferta de serviços no Alto Xingu. O que percebe-se nesse contexto de intermedicalidade é a convivência complexa entre duas formas de se definir o que é saúde e, portanto, de se lidar com a temática. Os profissionais não indígenas se esforçam para impor uma noção de saúde pautada nos conceitos biomédicos de cuidados e mesmo de corpo. Esse discurso muitas vezes é apreendido e reproduzido pelos próprios alto-xinguanos, mas quando observa-se mais de perto suas práticas, percebe-se que quando falam de "saúde", os alto-xinguanos estão, para além de reproduzindo um discurso externo, fazendo referência a um espaço político, especialmente acessado e utilizado pelas lideranças. Isso fica ainda mais claro quando se observam seus itinerários terapêuticos havendo, em geral, um privilegio das formas tradicionais de tratamento e cura 24

Nesse quadro, a multiplicação das alternativas terapêuticas e sua utilização de forma conjunta não conduzem, necessariamente, à diversificação dos modelos explicativos de causalidade e à "extinção" de culturas ou de determinadas práticas profiláticas. Percebe-se que os grupos 
indígenas procuram as terapias da medicina ocidental como uma alternativa frente a muitas outras possíveis, mantendo suas próprias formas de interpretação e de entendimento do processo de adoecimento. Todavia, apesar de ser apenas uma das opções possíveis, os alto-xinguanos não deixam de cobrar que o atendimento biomédico seja feito com qualidade (entendida aqui nos seus próprios termos) e por profissionais qualificados "que saibam trabalhar com o índio". Para "manter boas relações de trabalho" com as populações (e as lideranças) atendidas, os profissionais da EMSI precisariam ter uma atuação "diferente de como é na cidade", reconhecendo as especificidades do trabalho na aldeia e respondendo às demandas locais, ainda que isto muitas vezes contrarie a lógica biomédica.

Nesse contexto, os locais que possibilitam um maior contato entre diferentes práticas terapêuticas - os locais de fronteira - tornam-se privilegiados para a observação dessa relação complexa entre distintas concepções de saúde, e também possibilitam o surgimento de respostas híbridas, como consequência de uma releitura e ressignificação das práticas de tratamento e cura, com base na lógica de pensamento local.

No entanto, a atuação dos profissionais de saúde e demais representantes da medicina oficial nem sempre condiz com essa multiplicidade de possibilidades de escolha e de expectativas, não havendo espaços para a construção de conhecimentos e de práticas conjuntas, como se propõe no modelo de atenção à saúde indígena em vigor. É possível notar então, que os conflitos existentes entre as lideranças indígenas e os órgãos responsáveis pela gestão de saúde não se localizam propriamente na coexistência de distintos sistemas terapêuticos, mas sim na formulação de um modelo de atenção diferenciada pouco claro e que muitas vezes não contempla as demandas específicas dos agrupamentos indígenas. $\mathrm{O}$ modelo sugerido acaba por propor “ações padronizadas em saúde que podem, eventualmente, colidir tanto com o princípio de participação da população indígena na gestão dos serviços de saúde quanto com o pressuposto da integração dos sistemas terapêuticos indígenas nos seus quadros" 25 (p. 4).

É preciso então que se faça uma reavaliação criteriosa dos impactos desse modelo de atendimento à saúde, levando-se em consideração as demandas e as necessidades específicas dessas populações, bem como seus reflexos na cultura e na organização sociopolítica das aldeias (e com certeza, não apenas naquelas localizadas na região do Alto Xingu), considerando-se as distintas concepções e utilizações deste espaço eminentemente político das ações de saúde.

\section{Resumo}

O modelo de atenção à saúde indígena no Brasil tem como fundamentos a atenção integral à saúde, associada à noção de atenção diferenciada, e prevê o respeito à diversidade cultural, buscando a incorporação de práticas terapêuticas tradicionais nos serviços de saúde destinados a atender estas populações. A questão que se coloca é entender de que forma é possível conciliar o acesso universal aos bens e serviços de saúde a uma atenção que garanta a diferenciação, sem interferir, no entanto, na qualidade dos serviços ofertados. Para além disso, é preciso definir quais parâmetros utilizar para avaliar a qualidade e a eficácia des- ses serviços oferecidos em um contexto intercultural. Com base em um estudo de caso - a implementação dos serviços de saúde no Alto Xingu - apresento questões relacionadas aos usos políticos e os "perigos" associados aos "espaços da saúde" e as distintas concepções (de índios e não índios) do que seja saúde e qualidade dos serviços de saúde. Essas questões se interpõem e afetam não apenas as ações de saúde, mas também a situação política local.

Saúde Indígena; Atenção à Saúde; Qualidade, Acesso e Avaliação da Assistência à Saúde 


\section{Referências}

1. Organização Mundial da Saúde. Declaração de Alma-Ata. Conferência internacional sobre cuidados primários de saúde; Alma-Ata 1978. http://www. opas.org.br/promocao/uploadArq/Alma-Ata.pdf (acessado em 15/Ago/2008).

2. Ministério da Saúde/Fundação Nacional de Saúde. Política nacional de atenção à saúde dos povos indígenas. 2a Ed. Brasília: Ministério da Saúde/Fundação Nacional de Saúde; 2002.

3. Brasil. Lei no . 8080. Diário Oficial da União 1990; 20 set.

4. Brasil. Decreto no ${ }^{\circ}$. 3156, de 27 de agosto de 1999. Diário Oficial da União 1999; 28 ago.

5. Brasil. Lei no ${ }^{\circ}$ 9836, de 23 de setembro de 1999. Diário Oficial da União 1999; 24 set.

6. Brasil. Portaria $\mathrm{n}^{\mathrm{o}}$. 1163 , de 14 de setembro de 1999. Diário Oficial da União 1999; 15 set.

7. Mendes EV. Distritos sanitários: conceitos-chave. In: Mendes EV, organizador. Distrito Sanitário: o processo social de mudança das práticas sanitárias do Sistema Único de Saúde. São Paulo: Editora Hucitec/Rio de Janeiro: ABRASCO; 1999. p. 159-85.

8. Tassinari AMI. Escola indígena: novos horizontes teóricos, novas fronteiras de educação. In: Silva AL, Ferreira MKL, organizadores. Antropologia, história e educação. São Paulo: Global; 2001. p. 44-70.

9. Follér M-L. Intermedicalidade: a zona de contato criada por povos indígenas e profissionais de saúde. In: Langdon EJ, Garnelo L, organizadores. Saúde dos povos indígenas. Rio de Janeiro: Contra Capa/Associação Brasileira de Antropologia; 2004. p. $129-48$.

10. Atkinson SJ. Anthropology in research on the quality of health services. Cad Saúde Pública 1993; 9:283-99.

11. Minayo MCS. Abordagem antropológica para avaliação de políticas sociais. Rev Saúde Pública 1991; 25:233-8.

12. Augé M. L'anthropologie de la maladie. L'Homme 1986; 26:81-90.

13. Buchillet D, organizador. Medicinas tradicionais e medicina ocidental na Amazônia. Belém: CEJUP; 1991.
14. Garnelo L. Poder, hierarquia e reciprocidade: saúde e harmonia entre os Baníwa do Alto Rio Negro. Rio de Janeiro: Editora Fiocruz; 2003.

15. Langdon EJ. Cultura e processos de saúde e doença. In: Jeolás LS, Oliveira M, organizadores. Anais do seminário sobre Cultura, saúde e doença. Londrina: s/e; 2003. p. 91-107.

16. Langdon EJ, Garnelo L, organizadores. Saúde dos povos indígenas. Rio de Janeiro: Contra Capa/Associação Brasileira de Antropologia; 2004.

17. Santos RV, Coimbra Jr. CEA, organizadores. Saúde e povos indígenas. Rio de Janeiro: Editora Fiocruz; 1994.

18. Garnelo L, Sampaio S. Organizações indígenas e distritalização sanitária: os riscos de "fazer ver" e "fazer crer" nas políticas de saúde. Cad Saúde Pública 2005; 21:1217-23.

19. Verani CBL. Representações tradicionais da doença entre os Kuikuro (Alto Xingu). In: Buchillet D, organizador. Medicinas tradicionais e medicina ocidental na Amazônia. Belém: CEJUP; 1991. p. 65-88.

20. Barcelos Neto A. De divinações xamânicas e acusações de feitiçaria: imagens Wauja da agência letal. Mana 2006; 12:285-313.

21. Barcelos Neto A. O universo visual dos xamãs wauja (Alto Xingu). J Soc Am 2007; 87:137-60.

22. Viveiros-de-Castro E. Indivíduo e sociedade no Alto Xingu - os Yawalapiti. Rio de Janeiro: Museu Nacional; 1977.

23. Coelho-de-Souza MS. Virando gente: notas a uma história Aweti. In: Heckenberger M, Franchetto B, organizadores. Os povos do Alto Xingu: história e cultura. Rio de Janeiro: Editora da UFRJ; 2001. p. 360-402.

24. Novo MP. Os Agentes Indígenas de Saúde do Alto Xingu. Brasília: Paralelo 15; 2010.

25. Cardoso MD. Da pluralidade terapêutica à lógica da diferença: o contexto alto xinguano do Brasil Central. In: Anais da VI Reunião de Antropologia do Mercosul [CD-ROM]. Montevidéu: s/e; 2005.

Recebido em 27/Out/2010

Versão final reapresentada em 21/Jan/2011

Aprovado em 16/Mai/2011 